\title{
حرف العطف بين اللغتين العربية والإندونيسية (دراسة تحليلية تقابلية في كتاب القواعد الأساسية للغة العربية وكتاب BAHASA INDONESIA ILMIAH)
}

\author{
Zainab \\ (IAIN Madura/zainabjsarah@gmail.com)
}

\begin{abstract}
The book of Qawaid Asasiyat lilughatil 'Arabiyat is written by Ahmad alHasyimi bik bin Ibrahim bin Mustafa bin Muhammad Nafi'. This book contains the principles of Arabic such as the use of Arabic conjunctions. Meanwhile, the book of Bahasa Indonesia Ilmiah contains the principles of Indonesian which also explains about conjunctions. This research is aimed to know what types of conjunctions found in Qawaid Asasiyat Lilughatil 'Arabiyat book? The second focus is what types of conjunctions found in the book of Bahasa Indonesia Ilmiah? The third focus is how are the similarities and the differences between conjunctions in Qawaid Asasiyat lilughatil 'Arabiyat and in the book of Bahasa Indonesia Ilmiah. The data sources in this research were Qawaid Asasiyat lilughatil 'Arabiyat book, Nahwul Wadafi. Data collection procedures used was documentation, while the method utilized in this research was qualitative and contrastive content analysis. The results revealed that in the book of Qawaid Asasiyat lilughatil 'Arabiyat, there are nine types of conjunctions; wawu, fa', tsumma, hatta, aw, bal, laa, and lakinna. While, in the book of Bahasa Indonesia Ilmiah used four types of conjunctions, those are coordinating conjunctions, correlative conjunctions, subordinating conjunctions, and conjunctions that relate one sentence to another.
\end{abstract}

\section{Keywords:}

Conjunctions, Contrastive Analysis, Bahasa Indonesia Ilmiah, Qawaid Asasiyat lilughatil 'Arabiyat

DOI:10.19105/ojbs.v12i2.1998

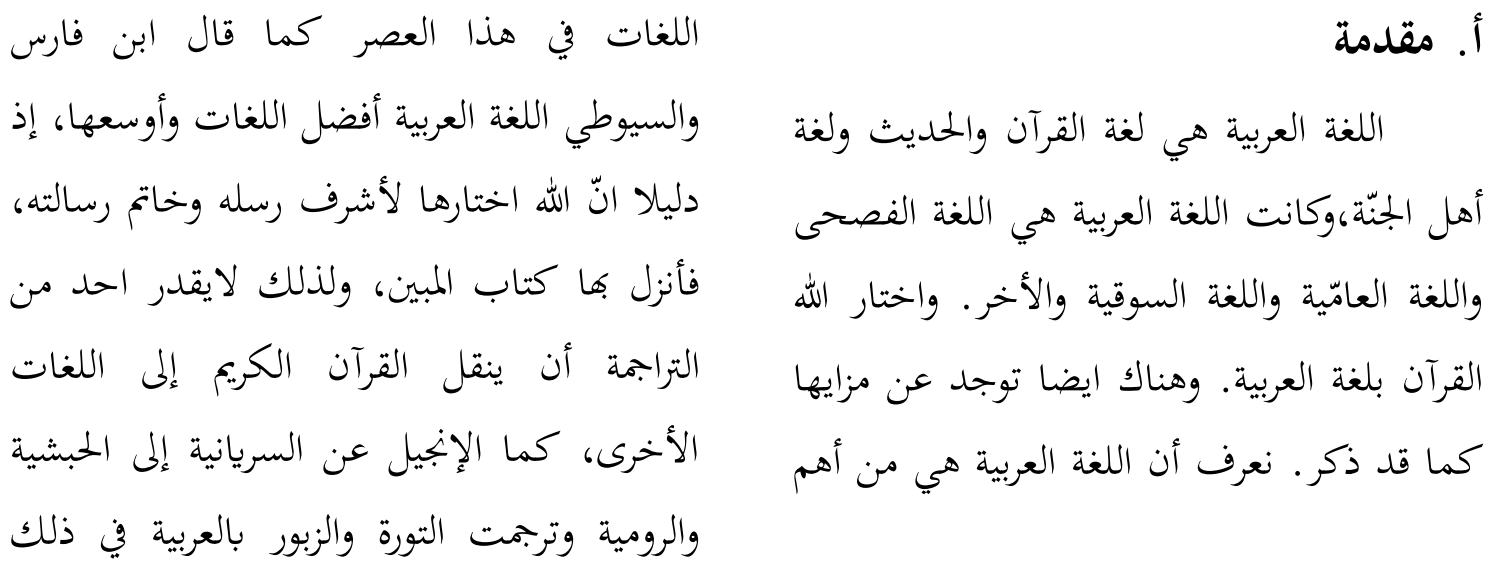


على اللغة التي هي موضوع التعليم واللغة الأولى 3

لمتعلم.

وهنا ايضا التحليل التقابلي لايترك لكل

متعلم هذه المهمّة، لأنّه قد لاينجح في " اكتشافه

" كما أنه قد يتوهم " تشابها " غير حقيقي، كما

هو الحال فيما يعرف " بالنظائر المخادعة ".

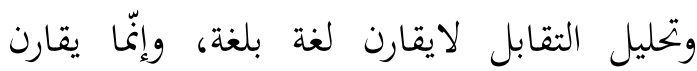

مستوى بمستوى، أو نظاما بنظام، أوفصيلة بفصيلة، ويجري التقابل على كل ماذكرنا آنفا: فالتقابل الصوتي مهم جدا في تعليم اللغة، وكذلك التقابل الصريف، والنحوي، والمعجمي.

كما قد عرفت هذا الباحثة أنّ حرف

العطف بين اللغتين على احد الكتاب هناك توجد

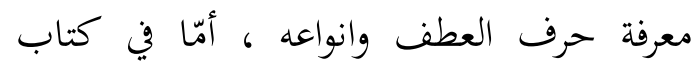

Bahasa Indonesia IImiah

معرفته وانواعه وظائفه. وبعد ذلك تأخد الموضوع الباحثة عن تحليل التقابلي بين حرف العطف في كتاب اللغة العربية والإندونيسية كما يلي.

عطف البيان تابع جامد يشبه النعت في

إيضاح متبوعه إن كان معرفة وفي تحصيصه إن كان نكرة بنفسه لابمعنى في متبوعه ولا في سببه

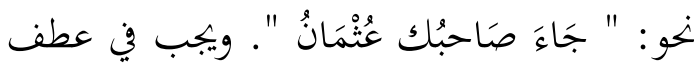
البيان أن يوافق متبوعُ في أنواع الإعراب والتذكير أو التأنيث والتعريف أوالتنكير والإفراد أو التثنية أو الجمع. وكل ماكان من عطف البيان يصحّ أن

3 عبده الرجمي، علم اللغة النطبيقي وتعليم العربية، جامعة الإمام حمح بن

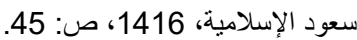

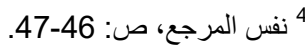

يعود إلى أنّ العجم لم تتسع في المجاز اتساع العرب.

وخصائص العربية نفسها لم تكتشف على

حقيقتها فيما كتبوه، إذا كان المؤلفون في هذه الخصائص يبحثون عنها متأثرين بالمنطق الأرسطي الذي لم تقف عدواه عند حد، فكان لها أثر في علم الكلام والفقه، مثلما كان لها أبلغ الأثار في دراسة اللغة.

كما قد عرفنا أنّ اللغة العربية يدرسها جميع المدارس الإسلامية في بلادنا، هي لغة دينية واللغة التي نزل بها القرآن الكريم، وفي زماننا الحديثة قد تطورت اللغة العربية سواء كان اللغة الانجليزية.تدرس اللغة العربية في المعاهد او المدراس الإسلامية في بلادنا، كلغة الإتصال او المكالمة في هذا العالم. contrastive ثمر طلم اللغة التقابلي linguistics لغوية واحدة أو عائلات لغوية مختلفة يهدف تيسير المشكلات " العملية " التي تنشأ عند التقاء هذه اللغات كالترجمة وتعليم اللغات الأجنبية. ويفضل علم اللغة التطبيق مصطلح التحليل التقابلي بدلا من علم اللغةالتقابلي: إذالمقصود هنا تحليل لغوي يجري

1إبوة ادريانا، فقه اللغة، الجامعة الإسلامية الحكومية بميكاسن: ص: 7 2بحبحي صالح، دراسات في فقه اللغة العربية، دار العلم للملايين

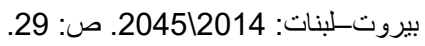


المنهج له دور هام في البحث العلمي

وهو مستخدم لبحث عن البيانات ووصفها.

والمنهج هو الأساليب والمداخل المتعددة التي

تستخدمها الباحثة في بناء النسق المعرف. 6

المنهج هو خطة العمل ، وهو في

الميدان المدارسى يشمل أنواع الخبرات

والدراسات التي توصلها المدرسة إلى التلاميذ. 7

والبحث هو وسيلة للاستعلام

والاستقصاء المنظم الدقيق التي تقوم به

الباحثة بغرض اكتشاف معلومات أوعلاقات

جديدة تؤدي إلى تطوير أو تصحيح أو تحقيق

المعلومات الموجودة أصلا. والعلم هو معرفة

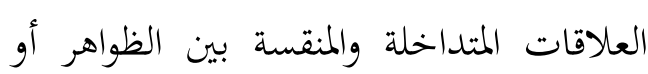

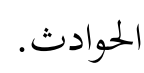

فمناهج البحث العلمي هي مجموعة

من الخطوات المنظمة والعلميات العقليات

والواعية والمبادئ العامة والطرق العملية التي

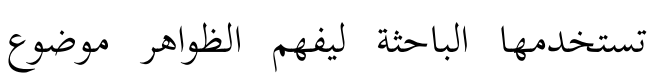

دراسته. قبل أن تبدأ الباحثة في كتابة البحث لئه

العلمي وجد كثيرا من المسائل المختلفة. ولذا،

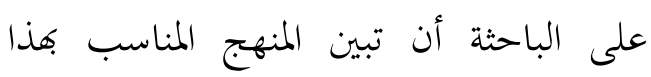

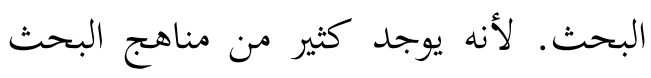

لكن ليس كلها موافقا بالأهداف المقصودة في

إجراء البحث.
يحلّ محلّ المعطوف عليه وهو يقبل الطرّح للاستغنا

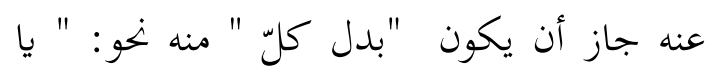
أخي عبد الله ".

حرف العطف باللغة الإندونيسية هي الكلمة الوظيفة التي وصلا الوحدة اللغة بدراجة الواحدة: الكلمة بالكلمة والعبارة بالعبارة. تحليل التقابل هو نظام علم اللغة واللغتين مثل: نظام الصوت ونظام القواعد. تحليل التقابل هنا ينتشر وتطبيقي في السنة 1950-1960 كعلم اللغة في تدريس اللغة. 5 تريد الباحثة أن ترتبط حرف العطف في لئ لئه هذا البحث لكي تعرف الاختلاف التي كانت في اللغة العربية واللغة الإندونيسية.

\section{ب. حدود البحث ومنهجه}

ولأجل تسهيل هذا البحث العلمي تريد الباحثة أن تحدد بحث وبيان كما يلي:

1. ما هي حرف العطف في كتاب القواعد الأساسية للغة العربية ؟

2. ماهي حرف العطف في كتا ب Bahasa ؟Indonesia Ilmiah 3. ما هي أوجه التشابه والاختلاف بين حرف العطف في كتاب القواعد الأساسية للغة Bahasa Indonesia وكتباب ?.llmiah

6 عبد الرحمن أحمد عثمان, مناهج البحث العلمى وطريقة كتابة

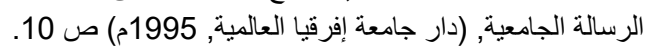

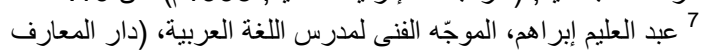

5 Henry Guntur Tarigan, Analisis Kontrastif Bahasa (Bandung: Angkasa, 1992), 5. 
د. منزلة توبيته

بعد انتهاء طلب العلم في الأزهر،

ويسكن في وقت طويل، وبدأ الشيخ أحمد

الها شمي في مرحلة التدريس، ثم هو يكون

المدرس في جامعة الأزهر، ثم هو يكون

مراقب في المدرسة فيكطريا (victoria)

حوالي خمسة وعشرون سنة، ثم يكون

المدير في مدرسة الرابطة ثم يكون المدير في

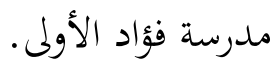

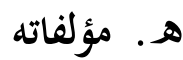

اشتمل أكثر مؤلفاته على مجال

التربية والتعليم وعددها تسعة كتب وكلها

مكتوبة باللغة العربية، ومن كتبه كما يلي:

1) جواهر الأدب في أدبيات وإنشاء لغة

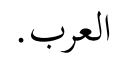

2) جواهر البلاغة في المعاني والبيان

$$
\text { والبديع. }
$$

3) ديوان الإنشاء أو أسلوب الحكيم في

$$
\text { منهج الإنشاء القويم. }
$$

4) السحر الحلال في الحلكم والأمثال.

5) السعادة الأبدية في الشريعة الإسلامية.

$$
\text { 6) القواعد الأساسية للغة العربية. }
$$

7) مختار الأحاديث النبوية والحكم المحمدية.

$$
\text { 8) المفرد العلم في رسم القلم. }
$$

9)ميزان الذهب في صناعة شعر العرب. 9
ج. عرض البيانات وتحليلها

1. لحة عن ترجمة حياة المؤلف (الشيخ أحمد

الماشئ)

أ. كنيته

الشيخ أحمد الها شمي بك بن

ابراهيم بن مصطفى بن تُمَّم نفيع ونصب

إليه على زين العابدين بن حسين بن علي

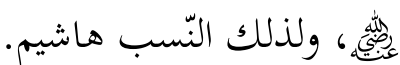

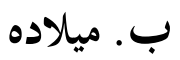

ولد في قرية زياد، وهي قرية مشهور

في مصر، فيسنة 1295 1878 م. 8

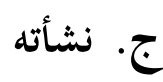

جاء الشيخ أحمد الها شمي مع جدّه

إلى الأزهر الشّريف ثم يحفظ القرآن الكريم

وبعض من المتن والعلم الذي يعلّمه في

تلك الجامعة وبعد ذلك إبتدأيتعلم العلوم

النقلية والعقلية إلى الأرشد المدرّس الأزهر

الاكبر، مثل: الشيخ الإسلام الأنبابي،

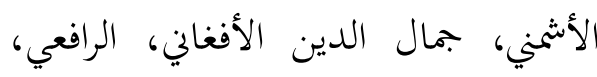

البحروي، الشربني، البوشري، الشيخ تُمَّمَ

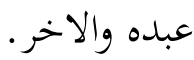

${ }^{9}$ Arianto.

${ }^{8}$ Ari Joni Arianto, "Mujahid Islam : Biografi Sayyid Ahmad Al-Hasyimi Bek," Mujahid Islam (blog), September

9 ,

2015 , http://mujahidislamq.blogspot.com/2015/09/biogra fi-sayyid-ahmad-al-hasyimi-bek_83.html. 
اسم المفعول، الصفة المشبهة، اسم

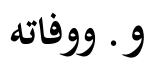

التفضيل، أسماء الزمان والمكان والآلة أفعال المدح والذم والتعجب. واختتم الكتاب في مات الشيخ أحمد الهاشمي، فيسنة 1943 هـ. وعمره 65 سنة وبعد أنيقضي البحث بنواصب الفعل المضارع وذلك في

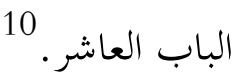
طول حياته بالتعلم والتدريس.

أ. لمحة عن القواعد الأساسية للغة العربية

ب.لمحة عن ترجمة حياة المؤلف (ورسمن

(warsiman

1

ولد (ورسمنwarsiman) في بجونكورو التاريخ 5 يونيو في السنة 1971، الولد التاسع من تسعة الولد، والده فلاح واسم أبوه جويوا أسطروا (Djoyo Astro) واسم امها المرحومة سريمة ( Almarhumah Sarimah). وبعد أن يخرج من المدرسة التربية المعلمين (SPG) في توبان في السنة 1990 ثم وصل درسته في الجامعة الحكومية إيكيف (IKIP) بسورابايا، وخريج في سنة 1993من دبلوم الثاني(D-2). هو المدرس في مدرسة كافوه كيدول الإبتدائية الحكومية(SDN Kepoh Kidul) بجونكورو في سنة (1998\2002) وخريج في سنة 2002 (S-2) وفي كلية التربية اللغة الإندونيسية، الحكومية بسورابايا (UNESA) والدكتور

10 Sayyid Ahmad Al-Hasimi, “القواعد الأساسية للغة 2018, http://s1.kitabklasik.net/2009/04/ffeed.html.
مضمون كتاب القواعد الأساسية

للغة العربية يتناول المؤلف البحث في القواعد الأساسية للغة العربية وقد نهى فيه منحى ألفية ابن مالك حيث جاء مرتبا حسب ترتيب هذه الألفية وضمن عشرة أبواب وتمهيد. عرض في التمهيد لمعنى النحو وللكالام وما يترتب عليه ولتعريف الفعل وتقسيمه ولمعينات المضارع وأحواله ولتعريف الحرف وبحث في الباب الأول في الإعراب والبناء ودار الباب الثاني حول النكرة والمعرفة وبين الباب الثالث الفاعل والمفعول وأحوالهما وجاء الباب الرّابع حول المبتدأ والخبر وتبعه البحث في الأفعال الناقصة وخصص الباب السادس للبحث في المنصوبات المفعول، المفعول المطلق، المفعول معه، المثنى، المنصوب. ودار البحث في الباب السابع حول مجرورات الأسماء: حروف الجر، معانيها، والإضافة وأنواعها. وبحث الباب الثامن في التوابع: النعت والتوكيد والبدل، ودار الباب التاسع حول عمل شبه الفعل، وفعل الجامد، واسم الفعل: المصدر وأنواعه، اسم الفاعل، 
وأحرف العطف تُنُبُ عن تكرار

عامل المعطوف عليه مع المعطوف. على

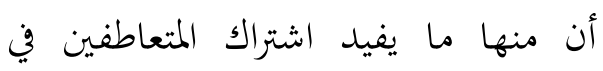
اللفظ والمعنى وهو" الواو، والفاء، وثم، لئح

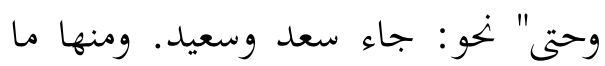

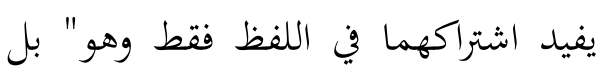
ولا ولكن" نخو : "جاء سليم لا خليل" وأما "أم-وأو" فتفيدان تارة اشتراكهما في اللفظ والمعنى -وتارة اشتراكهما في اللفظ فتط. تريد الباحثة أن تبين عن المضمون في كتاب القواعد الأساسية للغة العربية، تئه توجد هناك عن فهم التي تبحث حرف العطف تذكر فيها. وكانت أنواعه. ويعطوف الفعل على الفعل، ويعطف بين الجملتين بشرط اتفاقهما.

\section{ب. بأنواعه}

وأحرف العطف تسعة وهي: الواو،

والفاء، وثم، وحتى، وأو، وأم، وبل، ولا، ومي، الكاو،

1) الواو: لمطلق الجمع نحو: المال والبنون

زينة الحياة الدنيا.

2) الفاء: للترتيب والتعقيب نحو: أكبر

بلاد القطر مصر فالاسكندرية.

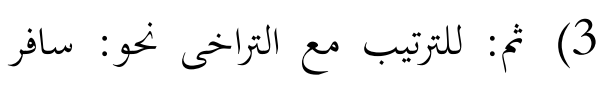

$$
\text { القواد ثم الجند }
$$

4) أو: للتخيير نحو: خذ درهما أو دينارا.
وخريج كلية التربية اللغة

الإندونيسية في سنة 2009. وكلية التربية

وجامعة التربية الإندونيسية في بندنية

ومنحة دراسيّة (BPPS (UPI)

كبرى لوزارة التربية والثقافة لجمهورية إندونيسية.

\section{د. عرض البيانات}

1. حرف العطف في كتاب القواعد الأساسية

للغة العربية

أ. تعريفه

عطف البيان تابع جامد يشبه

النعت في إيضاح متبوعه إن كان معرفة وفي تلئ

تحصيصه إن كان نكرة بنفسه لالمعنى في

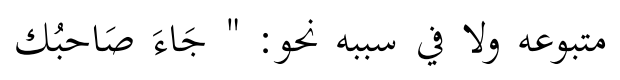

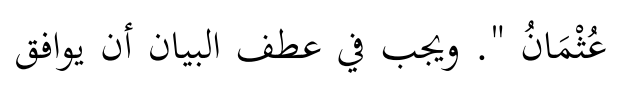

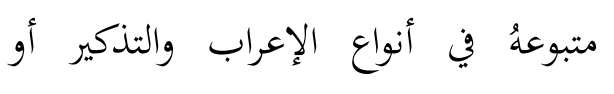

التأنيث والتعريف أوالتنكير والإفراد أو أو التئي

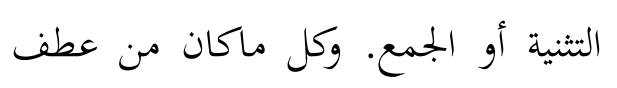
البيان يصحّ أن يجلّ محلّ المعطوف عليه

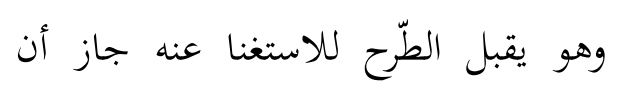

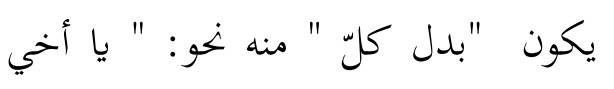
عبد الله ". 11

عطف النسق تابع يتوسط بينه وبين

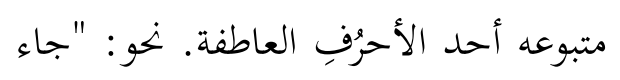
المعلم والرّيسيس -وقرأت الدّرس وكتبتُهُ".

2012. 11 أحمد الهاشمي، القواعد الأساسية للغة العربية، دار الكتب العلمية - بيروت: 
1) Penanda hubungan Dan/ وَعلامة الربط الزائدة (Dan)

Ari menangis dan adiknya pun tersedu-sedu.

$$
\text { يبكى اري وينشج اخي صغيره }
$$

Adik tertawa dan kakaknya pun turut terbahak-bahak.

يضحك اخي الصغير ويغرب

$$
\text { اخي كبيره }
$$

2) Serta penanda hubungan pendampingan

$$
\text { مَعَ يتصل علامة بجانب (Serta) }
$$

Dia mencari saya serta adik saya.

$$
\text { يطلبنى مع اخي صغيرتي }
$$

Warsiman membeli buku serta rak buku

$$
\text { يشترى ورسمن الدفتر مع رفّ الدفاتر }
$$

3) Atau penanda hubungan pemilihan.

$$
\text { (أَْْ علامة الرابطة الإنتخاب (Atau) }
$$

kau yang pergi atau aku yang meninggalkan tempat ini.

$$
\text { تذهب أو أترك هذا المكان }
$$

saya atau kamu yang akan mengantar Bapak.

$$
\text { أنا أو انت ليرافق اب }
$$

$$
\text { تحضر. أم: لأحد الشيئين نحو: أقريبا أم بعيداء }
$$

لكن: للاستدراك والنفي نحو: لاتمدح

$$
\text { الأشرار لكن الأخيار. }
$$

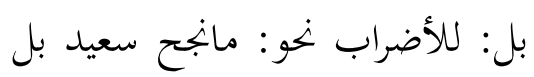

سعد.

$$
\text { لالا: للنفي السفو: جالس المؤدبين }
$$

$$
\text { حاشى: للغاية نحو: سافر الملك حتى } 12
$$

2. حرف العطف في اللغة الإندونيسية في كتاب

Bahasa Indonesia IImiah أ. تعريفه

حرف العطف في اللغة الإندونيسية الكلمة الوظيفة التي وصلا الوحدة اللغة بدراجة الواحدة: الكلمة بالكلمة والعبارة بالعبارة. 13
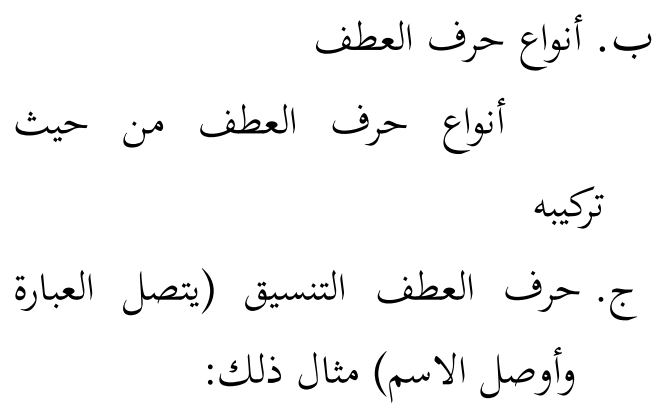

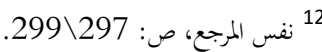

${ }^{13}$ Warsiman, Bahasa Indonesia IImiah (Malang: Universitas Brawijaya Press, 2013), 33. 
هو يتصنع بالعرف أن يعرف كثير. Mereka masih saja belum mengerti, padahal sudah diberitahu.

$$
\text { هم لايفهمون أن عرفوا. }
$$

7) Sedangkan

penanda

hubungan pertentangan

عَلَى علامة الرابطة (Sedangkan)

الخلالالمعاندة

مثل: مثل

Ibu sedang mencuci baju, sedangkan Bapak membaca koran.

$$
\text { الجنتسل أمي الثياب على يقرأ ابي }
$$

Adik makan roti, sedangkan kakak makan nasi.

$$
\begin{aligned}
& \text { يأكل اخي صغير الخبزعلى يأكل } \\
& \text { اخي كبير الرز }
\end{aligned}
$$

ح. استعمال حرف العطف ويبدل بينهما

$$
\text { على معنى غير واضح مثل: }
$$

1) Dan penanda hubungan pendampingan diganti dengan serta penanda hubungan pendampingan

$$
\begin{aligned}
& \text { موَ علا مة الرابطة المرافق ويبدل عليها } \\
& \text { Ari menangis serta } \\
& \text { adiknyapun tersedu-sedu. }
\end{aligned}
$$

$$
\text { يبكى اري مع ينشج اخي صغيره }
$$

4) Tetapi penanda hubungan perlawanan لكِينّ علامة الرابطة المعاندة (Tetapi)<smiles>[141IH]</smiles>

Dia terus saja berjalan, tetapi adiknya hanya mengikuti saja.

$$
\text { هو يمشى ولكن يتبع اخي الصغيره }
$$

Sebenarnya saya dapat mengerjakan, tetapi enggan membantu.

$$
\text { استطيع العمل ولكن يأبى ليساعد }
$$

5) Melainkan penanda hubungan perlawanan

$$
\begin{array}{r}
\text { إلَّلاّ علامة الرابطة (melainkan) } \\
\text { المعاندة }
\end{array}
$$

Bukan itu yang saya cari melainkan ini yang saya inginkan.

$$
\text { ليس ذلك ساطلب إلا هذا أريد }
$$

Bukan pertemuan yang ditangisi melainkan perpisahan yang disesali.

$$
\text { ليس اللقاء يبكى إلا الفراق انسحاق }
$$

6) padahal penanda hubungan pertentangan

$$
\begin{aligned}
& \text { أن علامة الرابطة (Padahal) } \\
& \text { الخلاف \المعاندة. } \\
& \text { مثل: }
\end{aligned}
$$


Sebenarnya saya dapat mengerjakan, namun enggan membantu.

$$
\text { أنا استطيع العمل لكن يأبى ليساعد }
$$

4) Melainkan penanda hubungan perlawanan diganti dengan padahal penanda hubungan pertentangan, atau diganti dengan pasangan kata yang tidak tepat.

إلَّا علامة الرابطة المعاندة ويبدل

$$
\text { بحرف العطف ومعنى غير واضيح. }
$$

Bukan itu yang saya cari padahal ini yang saya inginkan.

$$
\text { ليس ذلك اطلب إلا هذا أريد }
$$

Bukan aku yang salah, padahal dia yang memulai.

$$
\text { ليس انا الخطاء، ان يبدأ }
$$

5) Sedangkan penanda hubungan pertentangan diganti dengan sementara konjungsi subordinatif waktu.

$$
\begin{aligned}
& \text { على علامة الرابطة الخلاف \المعاندة }
\end{aligned}
$$

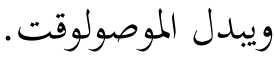

$$
\begin{aligned}
& \text { مثل: }
\end{aligned}
$$

Ibu sedang mencuci baju, sementara bapak membaca koran.

$$
\text { الجغتسل أمي الثياب على يقرأ ابي }
$$

Adik tertawa serta kakaknya pun turut terbahak-bahak.

$$
\text { كبيره }
$$

2) Serta penanda hubungan pendampingan diganti dengan dan penanda hubungan penambahan

مَعَ العلامة الرابطة المرافق ويبدل<smiles></smiles><smiles>[14CH3]</smiles>

Dia mencari saya dan adik saya.

$$
\text { هو يطلبني واخي الصغيرتي }
$$

Warsiman membeli buku dan rak buku.

$$
\text { يشتري ورسمن الدفتر ورف الدفاتر }
$$

3) Tetapi penanda hubungan perlawanan diganti dengan namun konjungsi antarkalimat, atau diganti dengan pasangan kata yang tidak tepat.

$$
\begin{aligned}
& \text { لَكِنَّ علامة الرابطة يبدل بكرف } \\
& \text { العطف بين الكلمات أو يبدل زوج } \\
& \text { الكلمة وغير مطابق. }
\end{aligned}
$$

Dia terus saja berjalan, tetapi adiknya hanya mengikuti saja.

$$
\text { هو يمشى لكن يتبع اخي الصغيره }
$$


أن حروف العطف في كتاب Bahasa

Indonesia IImiah التنسيق وحرف العطف المعلق وحرف العطف

يواصل العبارتين ولا سوى تراكيب الواحدة وحرف العطف بين الجملة.

أوجه التشابه والاختلاف بين حرف

العطف في كتاب القواعدالأساسية للغة العربية

وكتاب Bahasa Indonesia IImiah

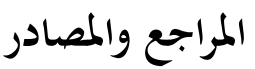 \\ المصادر اللغة العربية}

أحمد الهاشمي، القواعد الأساسية للغة العربية، دار

الكتب العلمية - بيروت: 2012. ص:

.295

إسوة ادريانا، فقه اللغة، الجامعة الإسلامية الحكومية بميكاسن

صبحي صالح، دراسات في فته اللغة العربية، دار

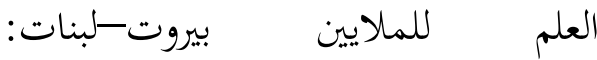

عبد الرحمن أحمد عثمان, مناهج البحث العلمى وطريقة كتابة الرسالة الجامعية, (دار جامعة

$$
\text { إفرقيا العالمية, 1995م) }
$$

عبد العليم إبراهم، الموجّه الفنى لمدرس اللغة العربية، (دار المعارف بمصر،1119)
Adik memakan roti, sementara kakak makan nasi.

يأكل اخي صغير الخبزعلى يأكل

$$
\text { اخي كبير الرز. }
$$

2. حرف العطف المعلق التي يواصل الكلمتين وعبارة سواء لتراكيب، ويعرف فيه بزوج كلمة وشوش استعمال زوج كلمة وإهتمام مثل حرف العطف أو يعرف بزوج كلمة جيدة 3. حرف العطف يواصل العبارتين ولاسوى تراكيب الوحدة من عبارة كلمات منظور من تراكيبو.

4. حرف العطف بين الجملة (يصيل الجملة واحدة بجملة أخر) ولذلك يبدأ بجملة جديدة وحرف الأول يكتب بحرف كبير، ثم يتبع علامة وفق قصير وتحديد بين عناصر موصلٌ وعناصر الجملة ويستعمل بين جملة وجملة أخر في وُجدَ كثرة اللغة الإندونيسية وحلّ به ليس لوقت جملة (جملة جديدة) وحرف أوله غير حرف كبير مثل: حرف العطف بين الجملة.

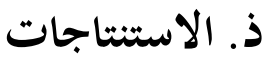

وبعد تحليل البيانات السابقة تقدمت الباحثة الاستنتاجات وهي كما يلي: أن حروف العطف في كتاب القواعد الأساسية للغة العربيةتسعة وهي: الواو، والفاء، وثم، وحتى، وأو، وأم، وبل، ولا، ولكن. 


$$
\text { جامبده الرجمي، علم اللغة التطبيقي وتعليم العربية، }
$$

Al-Hasimi, Sayyid Ahmad. " القواعد الأساسية لالعربية." Accessed March 14, 2018.

http://s1.kitabklasik.net/2009/04/ff eed.html.

Arianto, Ari Joni. "Mujahid Islam: Biografi Sayyid Ahmad AlHasyimi Bek." Mujahid Islam (blog), September 9, 2015. http://mujahidislamq.blogspot.co $\mathrm{m} / 2015 / 09 /$ biografi-sayyidahmad-al-hasyimi-bek_83.html.

Tarigan, Henry Guntur. Analisis Kontrastif Bahasa. Bandung: Angkasa, 1992.

Warsiman. Bahasa Indonesia IImiah. Malang: Universitas Brawijaya Press, 2013. 
